\title{
Patterns and Prevalence of Germline BRCA1 and BRCA2 Mutations among High-Risk Breast Cancer Patients in Jordan: A Study of 500 Patients
}

\author{
Hikmat Abdel-Razeq $\mathbb{D D}^{1,2}$ Lama Abujamous, ${ }^{3}$ and Dima Jadaan ${ }^{1}{ }^{1}$ \\ ${ }^{1}$ Department of Medicine, King Hussein Cancer Center, Amman, Jordan \\ ${ }^{2}$ School of Medicine, University of Jordan, Amman, Jordan \\ ${ }^{3}$ Department of Cell Therapy \& Applied Genomic, King Hussein Cancer Center, Amman, Jordan \\ Correspondence should be addressed to Hikmat Abdel-Razeq; habdelrazeq@khcc.jo
}

Received 25 April 2020; Accepted 22 June 2020; Published 14 July 2020

Academic Editor: Pierfrancesco Franco

Copyright (c) 2020 Hikmat Abdel-Razeq et al. This is an open access article distributed under the Creative Commons Attribution License, which permits unrestricted use, distribution, and reproduction in any medium, provided the original work is properly cited.

\begin{abstract}
Purpose. Knowledge of BRCA1 and BRCA2 mutations has a significant clinical impact on the management and prevention of breast cancer. In this study, we evaluate the pattern and prevalence of germline mutations in BRCA1 and BRCA2 among high-risk Jordanian breast cancer patients selected as per international guidelines. Methods. BRCA1 and BRCA2 testing were performed at a reference genetic lab. Mutations were classified as pathogenic/likely pathogenic and variant of uncertain significance (VUS). Results. A total of 517 patients, median age: 39 (range: 19-78) years, were enrolled. Among the whole group, 72 (13.9\%) patients had pathogenic or likely pathogenic BRCA1 $(n=24,4.6 \%)$ or BRCA2 $(n=48,9.3 \%)$ mutations, while $53(10.3 \%)$ others had VUS. Among 333 younger ( $\leq 40$ years) patients, mutations were observed in $44(13.2 \%)$. Positive mutations were found in $40(16.5 \%)$ patients with one or more close relatives with breast cancer and in 20 (35.1\%) of the 57 patients with triple-negative disease. Multivariate analysis showed that a triple-negative status, history of two or more close relatives with breast cancer, and history of one or more close relatives with invasive ovarian cancer were associated with significant high odds ratios (OR) of carrying a pathogenic variant, with an OR (95\% CI) of 5.08 (2.66-9.67), 3.24 (1.78-5.89), and 2.97 (1.04-8.52), respectively. Conclusions. BRCA1 and BRCA2 mutations are not uncommon among Jordanian patients. Young age has the weakest association with positive mutations, while patients with triple-negative disease, especially those with an additional positive family history, have the highest mutation rate.
\end{abstract}

\section{Introduction}

Accounting for almost $20 \%$ of all cancer cases, breast cancer continues to be the most common cancer and the leading cause of cancer-related deaths among Jordanian women. A total of 1145 cases were reported by the Jordan Cancer Registry in its latest annual report [1]; more than $60 \%$ of them are treated at our center. Almost $50 \%$ of breast cancer patients are diagnosed at the age of 50 or younger. Regionally, more than a third of patients present with locallyadvanced or metastatic disease $[2,3]$.

Published data had shown that $5-10 \%$ of breast cancer is hereditary and mostly related to $B R C A 1$ or $B R C A 2$ gene mutations [4, 5]. Efforts to identify such mutations are extremely important given the high penetrance rates among its carriers [6]. In a meta-analysis of published studies, the estimated mean cumulative risk for breast and ovarian cancers by 70 years of age for BRCA1 mutation carriers were $57 \%$ and $40 \%$, respectively, while carriers of BRCA2 mutation had a risk of $49 \%$ and $18 \%$, respectively [7]. Risk-reduction interventions, such as bilateral mastectomies and oophorectomies, are highly recommended in such patients. More recently, data had shown that specific breast cancer treatment may be informed by the BRCA1 or $B R C A 2$ mutation status. In patients with advanced breast cancer associated with $B R C A 1$ or BRCA2 mutations, olaparib and talazoparib are now approved for treatment [8-11]. 
Data related to hereditary breast cancer among the Arab countries in general, and Jordan in particular, are scarce, and ranges of positive rates are very wide [12-18]. Knowledge about the pattern and prevalence of ancestry-specific prevalence of $B R C A 1$ and $B R C A 2$ mutations can help policy makers tailor counselling, prevention, and treatment strategies that can better help our particular patients. We recently reported our experience with 100 high-risk patients (median age: 40 , range: $22-75$ years) treated and followed at our institution. In total, $20(20.0 \%)$ patients had deleterious (pathogenic) and 7 (7.0\%) others had suspected deleterious (likely pathogenic) mutations in BRCA1 or BRCA2 genes. Highest mutation rates were observed among patients with triple-negative disease (negative for estrogen receptors (ER), progesterone receptors (PR), and human epidermal growth factor (HER2) receptors), especially among those with a positive family history of breast and/or ovarian cancer, patients with bilateral or second primary breast cancer, and those with a family history of male breast cancer [19].

The aim of our study is to evaluate, in a larger group of patients, the contribution of germline mutations in $B R C A 1$ and $B R C A 2$ to breast cancer among Jordanian patients with selected high-risk profile as per the National Comprehensive Cancer Network (NCCN) guidelines [20].

\section{Methods}

Jordanian breast cancer patients with selected high-risk profile, as per the NCCN guidelines [20], were invited for $B R C A 1$ and BRCA2 testing. This includes patients of 40 years of age or younger at the time of breast cancer diagnosis, patients with at least two breast cancer primaries (i.e., bilateral tumors or 2 or more clearly separate ipsilateral tumors, occurring synchronously or asynchronously), the first at the age of 50 years or younger, patients diagnosed at the age of 50 years or younger with one or more close relatives with breast cancer at any age, diagnosed at any age with 2 or more close relatives with breast cancer at any age, diagnosed at any age with one or more close relatives with invasive ovarian cancer diagnosed at any age, diagnosed at any age with a close male relative with breast cancer at any age, and patients with triple-negative disease who are 60 years of age or younger [20]. All patients had their diagnosis, treatment, and follow-up at our center.

Eligible patients were identified by their primary oncologists during their routine clinic visit or during the weekly breast multidisciplinary team (MDT) discussion. Patients who consented to BRCA1 and BRCA2 testing were then referred to our genetic counseling clinic where a lengthy interview and discussion by a trained genetic counselor were carried out. Clinical and psychosocial consequences of positive test results were discussed at length with the patients, and when requested by the patient, such meeting and discussion were also carried out with the spouse and/or family members.

The study was discussed and approved by our Institutional Review Board (IRB), and all patients signed informed consent. BRCA1 and BRCA2 testing were performed at no cost to participants as per part of the routine clinical practice. Ten milliliters of peripheral blood samples were obtained for DNA extraction. BRCA1 and BRCA2 sequencing were performed at Leeds Cancer Center, Leeds, United Kingdom. Based on a standardized variant assessment tool used by reference genetics labs, BRCA1 and $B R C A 2$ mutations were classified as pathogenic/likely pathogenic (positive) and variant of uncertain significance (VUS). Clinical and pathological data were obtained from patients' medical records, and a detailed 3-generation family history was also obtained by a genetic counselor or one of the investigators.

Analysis was performed using an Agilent SureSelect custom design reagent to screen for germline pathogenic variants. Genomic DNA regions including coding exons and intron/exon boundaries are targeted by hybridization capture and sequenced on the Illumina platform with a sensitivity of at least 95\%. The target region of selected transcripts is covered to a minimum read depth of $30 \mathrm{x}$. Analysis for large deletion and duplication is preformed using comparative depth of coverage of NGS data and/or MLPA analysis using P087, P045, and P260.

2.1. Statistical Analysis. Patient characteristics were tabulated and described by ranges, medians, or percentages (\%). Firstdegree close relatives diagnosed with breast cancer and tested later to the index case in the family were excluded from analyses. The $\chi 2$ test or Fisher exact test were used to compare the proportion of positive BRCA1 and BRCA2 pathogenic/ likely pathogenic mutations according to the age ( $\leq 40$ versus $>40$ ), triple-negative status, first- and/or second-degree family history of breast and/or ovarian cancer, bilateral or second primary breast cancer, number of indications for genetic testing, and family history of male breast cancer. Multivariate analysis using a logistic regression model adjusting for the age, triple-negative status, and bilateral or second primary breast cancer was performed. Odds ratios and their related $95 \%$ confidence intervals (CI) were calculated. A $P$ value $\leq 0.05$ was considered significant. Version 9.4 of SAS software (SAS Institute Inc., Cary, NC) was utilized.

\section{Results}

Between November 2016 and January 2019, a total of 517 consecutive eligible patients were recruited. The median age of participants was 39 (range: 19-78) years. At the time of diagnosis, $333(64.4 \%)$ patients were 40 years of age or younger. Majority $(n=420,81.2 \%)$ of the patients had hormone receptor (ER and/or PR) positive disease. Human epidermal growth factor receptor (HER2) was positive in 133 (25.7\%) by immunohistochemistry (IHC) and/or Fluorescent In Situ Hybridization (FISH), and 57 (11.0\%) had triplenegative disease, Table 1.

Among the whole group, $72(13.9 \%)$ patients had pathogenic/likely pathogenic BRCA1 or BRCA2 mutations; $48(66.7 \%)$ of them were in BRCA2, while $24(33.3 \%)$ in BRCA1 and an additional $53(10.3 \%)$ patients had VUS. A total of $242(46.8 \%)$ had their genetic testing because they were 50 years of age or younger with one or more close 
TABle 1: Patient characteristics $(n=517)$.

\begin{tabular}{|c|c|c|c|}
\hline \multicolumn{2}{|c|}{ Characteristics } & \multirow{2}{*}{$\begin{array}{c}\text { Number } \\
39 \\
19-78\end{array}$} & \multirow[t]{2}{*}{$(\%)$} \\
\hline Age at diagnosis (years) & $\begin{array}{c}\text { Median } \\
\text { Range }\end{array}$ & & \\
\hline \multirow{4}{*}{ Hormonal status } & ER-positive & 392 & 75.8 \\
\hline & PR-positive & 375 & 72.5 \\
\hline & ER- or PR-positive & 420 & 81.2 \\
\hline & ER- and PR-negative & 97 & 18.8 \\
\hline \multirow{3}{*}{ HER2 status } & HER2-positive & 133 & 25.7 \\
\hline & HER2-negative & 318 & 61.5 \\
\hline & Unknown & 66 & 12.7 \\
\hline Triple-negative & & 57 & 11.0 \\
\hline Positive family history o & breast cancer & 441 & 85.3 \\
\hline
\end{tabular}

ER: rstrogen receptors; PR: progesterone receptors; HER2: human epidermal growth factor receptor.

relatives with breast cancer at any age; $40(16.5 \%)$ of them were positive for $B R C A 1$ or $B R C A 2$. Among the 333 patients who were 40 years of age or younger, the pathogenic/likely pathogenic mutations were observed in $44(13.2 \%)$ patients, Table 2.

Twenty (35.1\%) of the 57 patients with triple-negative disease had pathogenic/likely pathogenic mutations; 16 $(80.0 \%)$ of them were in BRCA1, and only $4(20.0 \%)$ were in $B R C A 2$. An additional 7 (12.3\%) others had VUS. Among 37 patients with triple-negative disease who were 40 years of age or younger, $12(32.4 \%)$ were positive; all except 2 were in $B R C A 1$. Among the patients with triple-negative disease who have a family history of breast cancer diagnosed at an age $<50(n=12), 5(41.7 \%)$ were BRCA1- or BRCA2-positive. Another 5 (55.6\%) of those with two family members with breast cancer at any age $(n=9)$ were positive for pathogenic mutation too. Figure 1 illustrates the mutation rates among patients tested for different indications, while Figure 2 details mutation rates among subgroups of patients with triplenegative disease.

We also reviewed the mutation rates based on the number of indications a patient may have had for testing. Among 205 (39.7\%) patients who had only one indication as per the NCCN guidelines, only 12 (5.9\%) had pathogenic or likely pathogenic mutation compared to 25 (15.1\%) among 166 (32.1\%) patients with two indications and 35 (24.0\%) among $146(28.2 \%)$ patients with three or more indications. No founder mutation was identified, and the type and frequency of specific mutations are illustrated in Table 3.

Multivariate analysis using a logistic regression model was performed. The triple-negative status, history of two or more close relatives with breast cancer, and history of one or more close relatives with invasive ovarian cancer were significant with an OR of carrying a pathogenic variant (95\% CI) of $5.08 \quad(2.66-9.67), \quad 3.24 \quad(1.78-5.89)$, and 2.97 (1.04-8.52), respectively (Table 4 ).

\section{Discussion}

This is the biggest $B R C A 1$ and $B R C A 2$ mutation study from Jordan and one of the biggest from the region. Our data showed that such mutations are not uncommon among
Jordanian patients selected and tested as per the NCCN guidelines. Contrary to what is usually seen in western societies, our data indicate that mutation rates are not higher among the younger patients (13.2\%) compared to the whole group (13.9\%), obviously all with at least one risk factor. The fact that breast cancer is diagnosed at a younger age in our region can be a factor. We are in the process of combining the cohort of younger patients included in this study and our previous one [19] to study the contribution of age, in the absence of other risk factors, to the risk of carrying $B R C A 1$ or BRCA2 mutation.

We also noted relatively high rates of VUS in this group of patients. This could likely be related to racial issues as western reference laboratories might not have enough exposure to the specific mutations encountered in our population. Mutation testing in our previously published study [19] was conducted at a different reference laboratory and had a similar high VUS rate, making the racial hypothesis an interesting one to follow.

Patients with triple-negative disease had the highest mutation rate and, as expected, mostly (80\%) in BRCA1. Given this high positive pathogenic mutation rate, additional risk factors did not add to the already high mutation rate. The only exception is probably the presence of a family history of breast cancer in at least two family members. However, studies including a larger number of such patients are needed to address this issue. In addition to patients with triple-negative disease, patients with at least two breast primaries had higher mutation rate (21.7\%).

Our positive mutation rates are significantly higher than what our colleagues had recently reported among 281 Lebanese patients [21]. Though it was stated that patients were tested as per NCCN guidelines for mutation screening, the prevalence of mutated $B R C A 1$ or $B R C A 2$ genes was only $6.0 \%$ and $1.4 \%$, respectively. In an earlier study, reported by the same group, on 250 Lebanese patients tested between 2009 and 2012 who were considered to be at high risk of carrying $B R C A 1$ or BRCA2 mutations because of presentation at a young age and/or a positive family history of breast or ovarian cancer, $14(5.6 \%)$ carried a deleterious mutation (7 BRCA1, 7 BRCA2) and 31 (12.4\%) carried VUS. In the same study, only one (1.4\%) of the 74 patients aged $\leq 40$ years without a family history had pathogenic mutation, while $8(10.8 \%)$ of the 74 patients aged $\leq 40$ years with a positive family history had a deleterious mutation [22]. On the other hand, a recent systematic review and meta-analysis of 14 studies from the region attempted to better describe the prevalence of $B R C A 1$ and $B R C A 2$ mutations in Arab countries. The study has several methodology problems, yet they reported a high rate of $20 \%$. [23].

We have no explanation on the significant differences between our rates and what had been reported among the Lebanese. There should be no significant ethnic differences that may account for such variation. In our database, 63 nonJordanian patients from Syria, Iraq, Libya, and Palestine and not included in our analysis were tested for BRCA1 and BRCA2 mutation following the same indications and methodology of testing, and $8(12.7 \%)$ had positive mutations. Different inclusion criteria for testing or different 
TABLE 2: Rates of positive BRCA1 and BRCA2 mutation across different indications.

\begin{tabular}{|c|c|c|c|c|c|c|}
\hline \multirow[b]{2}{*}{ Variable } & & \multirow[b]{2}{*}{ Total } & \multicolumn{4}{|c|}{ Positive mutations } \\
\hline & & & $B R C A 1$ & $B R C A 2$ & $\begin{array}{l}B R C A 1 \text { and } \\
B R C A 2\end{array}$ & $\begin{array}{c}P \\
\text { value* }^{*}\end{array}$ \\
\hline Age at diagnosis (years) & $\begin{array}{l}\leq 40 \\
>40\end{array}$ & $\begin{array}{l}333 \\
184\end{array}$ & $\begin{array}{l}15(4.5 \%) \\
9(4.9 \%)\end{array}$ & $\begin{array}{c}29(8.7 \%) \\
19(10.3 \%)\end{array}$ & $\begin{array}{l}44(13.2 \%) \\
28(15.2 \%) \\
\end{array}$ & 0.530 \\
\hline $\begin{array}{l}\text { Age } \leq 50 \text { years with one or more close relatives with breast cancer at any } \\
\text { age }\end{array}$ & $\begin{array}{l}\text { Yes } \\
\text { No }\end{array}$ & $\begin{array}{l}242 \\
275\end{array}$ & $\begin{array}{c}8(3.3 \%) \\
16(5.8 \%) \\
\end{array}$ & $\begin{array}{l}32(13.2 \%) \\
16(5.8 \%)\end{array}$ & $\begin{array}{l}40(16.5 \%) \\
32(11.6 \%)\end{array}$ & 0.1 \\
\hline Age $\leq 60$ with triple-negative disease & $\begin{array}{l}\text { Yes } \\
\text { No }\end{array}$ & $\begin{array}{c}57 \\
460 \\
\end{array}$ & $\begin{array}{c}16(28.1 \%) \\
8(1.7 \%)\end{array}$ & $\begin{array}{c}4(7.0 \%) \\
44(9.6 \%)\end{array}$ & $\begin{array}{l}19(35.1 \%) \\
53(11.5 \%)\end{array}$ & $<0.001$ \\
\hline Any age with at least 2 breast cancer primaries & $\begin{array}{l}\text { Yes } \\
\text { No }\end{array}$ & $\begin{array}{c}57 \\
460\end{array}$ & $\begin{array}{c}4(7.0 \%) \\
20(4.3 \%)\end{array}$ & $\begin{array}{c}4(7.0 \%) \\
44(9.6 \%)\end{array}$ & $\begin{array}{c}8(14.0 \%) \\
64(13.9 \%)\end{array}$ & 0.98 \\
\hline Any age with 2 or more close relatives with breast cancer & $\begin{array}{l}\text { Yes } \\
\text { No }\end{array}$ & $\begin{array}{l}115 \\
402\end{array}$ & $\begin{array}{c}7(6.1 \%) \\
17(4.2 \%)\end{array}$ & $\begin{array}{c}21(18.3 \%) \\
27(6.7 \%)\end{array}$ & $\begin{array}{l}28(24.3 \%) \\
44(10.9 \%)\end{array}$ & $<0.001$ \\
\hline $\begin{array}{l}\text { Any age with one or more close relatives with invasive ovarian cancer } \\
\text { diagnosed at any age }\end{array}$ & $\begin{array}{l}\text { Yes } \\
\text { No }\end{array}$ & $\begin{array}{c}19 \\
498\end{array}$ & $\begin{array}{l}2(10.5 \%) \\
22(4.4 \%)\end{array}$ & $\begin{array}{l}4(21.1 \%) \\
44(8.8 \%)\end{array}$ & $\begin{array}{l}6(31.6 \%) \\
66(13.3 \%)\end{array}$ & 0.023 \\
\hline All patients & & 517 & $24(4.6 \%)$ & $48(9.3 \%)$ & $72(13.9 \%)$ & \\
\hline
\end{tabular}

${ }^{*} P$ value comparing risk factor categories.

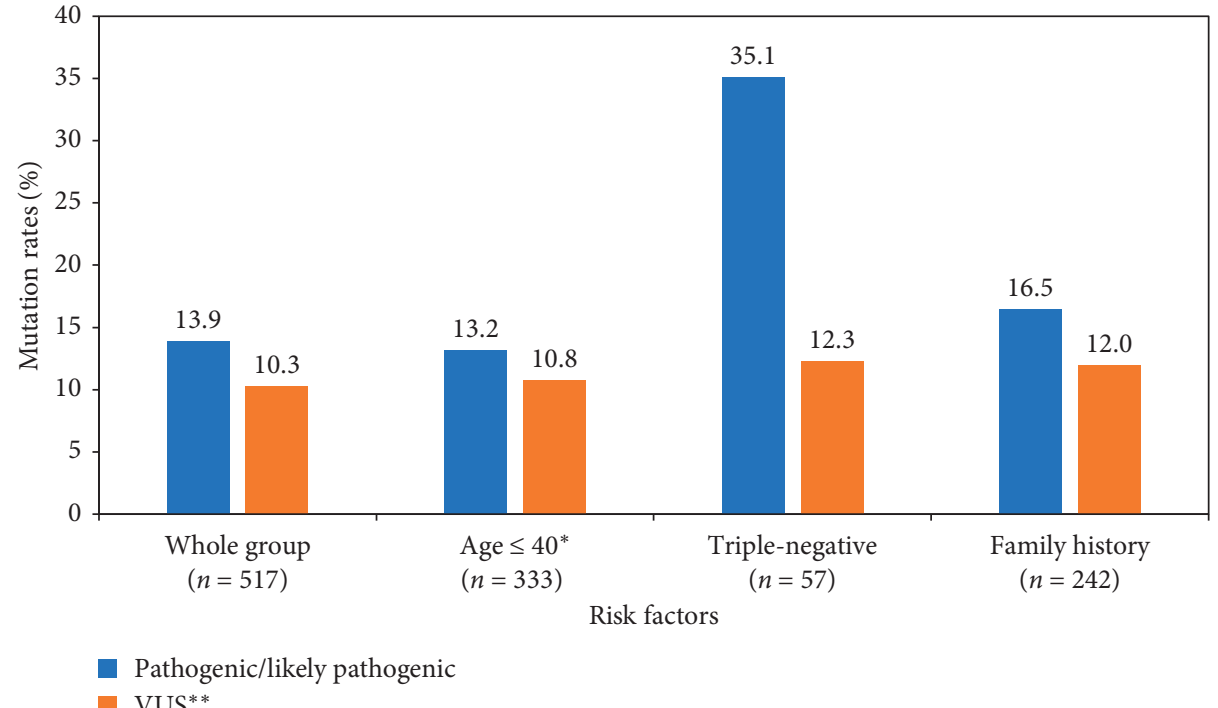

FIgURE 1: BRCA1and BRCA2 mutation rates by indication.

testing methodologies may have contributed to this variation in mutation rates.

In our previous study, we addressed the challenges in conducting such studies in a culturally sensitive society with limited resources. Many ethical and cultural difficulties were encountered and continued to be encountered during the course of our study. Ensuring confidentiality and privacy are still major issues in a closely related, relatively small community. However, very few patients (4 patients) expressed their concerns about labeling and stigmatization and, thus, refused the testing when approached by their physicians. Additionally, none of the patients tested positive had issues with sharing and addressing such results with their at-risk family members. Local or regional data on clinical and psychosocial consequences related to positive mutations are lacking. We are in the process of collecting such data as part of a larger genetic testing and genetic counselling project.

Potential employment and social discrimination addressed in our previous report had not surfaced out as major issues in expanding our program. However, insurance issues continued to be a problem. Though governmental cancer care insurance covers for BRCA1 and BRCA2 testing, it does not cover the major part of the reconstruction surgery.

Now that we confirm that BRCA1 and BRCA2 mutations are not uncommon, such testing, counseling, and linking it to risk-reduction surgery should be incorporated into the routine clinical practice nationwide. At our institution, genetic testing has become routinely offered for at-risk patients as per the published NCCN guidelines. 


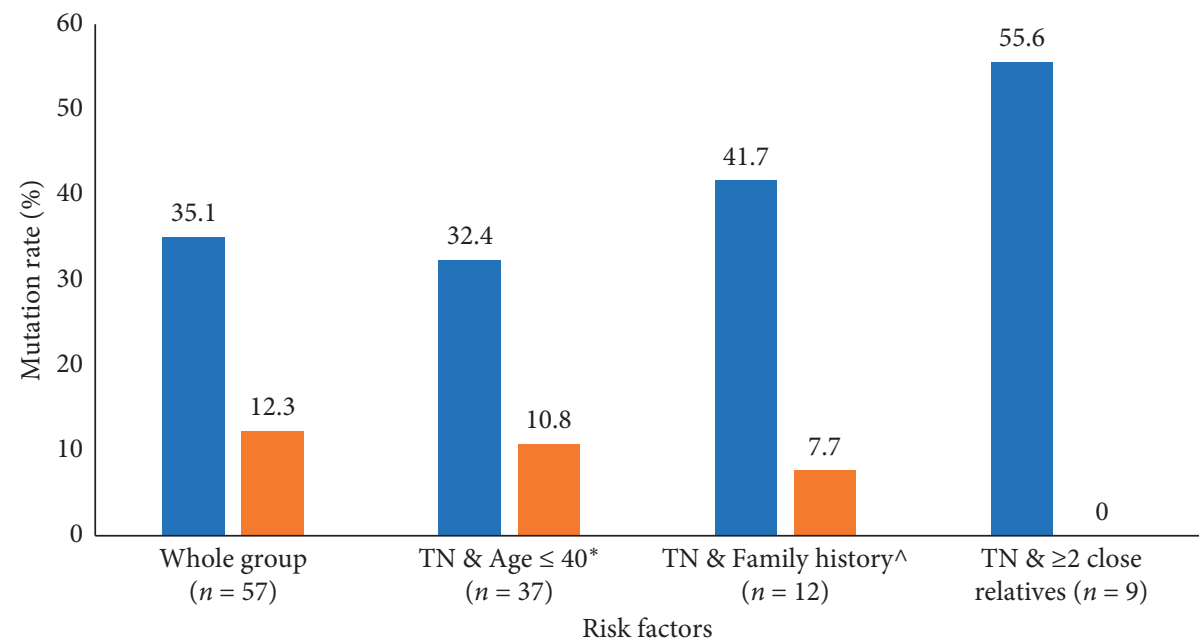

Pathogenic/likely pathogenic

VUS**

FIGURE 2: BRCA1and BRCA2 mutations among patients with triple-negatives.

TABLE 3: Frequency of BRCA1 and BRCA2 mutations.

\begin{tabular}{|c|c|c|c|c|c|c|c|c|}
\hline Gene & Exon/intron & $\begin{array}{l}\text { Nucleotide } \\
\text { change }\end{array}$ & Amino acid change & Variant type & dbSNP rs & Clinical significance & $\begin{array}{l}\text { Database } \\
\text { report }\end{array}$ & $\begin{array}{c}\text { Frequency } \\
(n)\end{array}$ \\
\hline$B R C A 1$ & Exon 2 & c.66dup & p.Glu23Arg & $\begin{array}{c}\text { Duplication/ } \\
\text { fs }\end{array}$ & rs 80357783 & Pathogenic & Yes & 5 \\
\hline$B R C A 1$ & Exon 12 & c. $4117 \mathrm{G}>\mathrm{T}$ & p.Glu1373Ter & Nonsense & rs80357259 & Pathogenic & Yes & 3 \\
\hline$B R C A 1$ & Intron 17 & c. $5074+3 \mathrm{~A}>\mathrm{G}$ & Splice acceptor & $\begin{array}{l}\text { Intervening } \\
\text { sequence }\end{array}$ & rs80358181 & Likely pathogenic & Yes & 3 \\
\hline BRCA1 & Exon 11 & c.4065_4068del & p.Asn1355Lys & Deletion/fs & rs80357508 & Pathogenic & Yes & 2 \\
\hline BRCA1 & Exon 18 & c. $5123 \mathrm{C}>\mathrm{A}$ & p.Ala1708Glu & Missense & rs28897696 & Pathogenic & Yes & 2 \\
\hline BRCA1 & Exon 3 & c. $121 \mathrm{C}>\mathrm{T}$ & p.His41Tyr & Missense & rs 1060502353 & Likely pathogenic & Yes & 2 \\
\hline$B R C A 2$ & Exon 11 & $\begin{array}{c}\text { c.2254_2257 } \\
\text { del }\end{array}$ & p.Asp752Phefs & Deletion/fs & rs80359326 & Pathogenic & Yes & 8 \\
\hline$B R C A 2$ & $\begin{array}{l}\text { Exon 11/ } \\
\text { Exon } 11\end{array}$ & $\begin{array}{l}\text { c.2254_2257 } \\
\text { del \& c.5351 } \\
\text { dup }\end{array}$ & $\begin{array}{l}\text { p.Asp752Phefs and } \\
\text { p.Asn1784Lysfs }\end{array}$ & $\begin{array}{l}\text { Deletion/fs- } \\
\text { Duplication/ } \\
\text { fs }\end{array}$ & $\begin{array}{c}\text { rs80359326 \& } \\
\text { rs80359508 }\end{array}$ & Pathogenic & Yes & 6 \\
\hline$B R C A 2$ & Exons 5-11 & $\begin{array}{c}\text { Partial } \\
\text { duplication } \\
\text { (exons 5-11) }\end{array}$ & $\begin{array}{l}\text { Absent or disrupted } \\
\text { protein product }\end{array}$ & $\begin{array}{c}\text { Large } \\
\text { duplication }\end{array}$ & - & Pathogenic & Yes & 5 \\
\hline$B R C A 2$ & Exon 10 & c.1233dup & p.Pro412Thr & $\begin{array}{c}\text { Duplication/ } \\
\text { fs }\end{array}$ & rs80359270 & Pathogenic & Yes & 3 \\
\hline BRCA2 & Exon 11 & c. $6685 \mathrm{G}>\mathrm{T}$ & p.Glu2229Ter & Nonsense & rs730881548 & Pathogenic & Yes & 3 \\
\hline$B R C A 2$ & Exon 11 & c.6486_6489del & p.Lys2162Asn & Deletion/fs & rs80359598 & Pathogenic & Yes & 2 \\
\hline$B R C A 2$ & Intron 24 & c. $9257-1 \mathrm{G}>\mathrm{A}$ & Splice acceptor & $\begin{array}{c}\text { Intervening } \\
\text { sequence }\end{array}$ & rs 81002889 & Likely pathogenic & Yes & 2 \\
\hline
\end{tabular}

TABLE 4: Logistic regression.

\begin{tabular}{|c|c|c|c|}
\hline Variable & Odds ratio & $95 \% \mathrm{CI}$ & $P$ value \\
\hline Age at diagnosis $<40$ & 1.27 & $0.71-2.28$ & 0.40 \\
\hline Triple negative & 5.08 & $2.66-9.67$ & $<0.0001$ \\
\hline Bilateral or second primary breast cancer & 1.01 & $0.43-2.36$ & 0.99 \\
\hline History of two or more close relatives with breast cancer & 3.24 & $1.78-5.89$ & 0.0001 \\
\hline History of one or more close relatives with invasive ovarian cancer & 2.97 & $1.04-8.52$ & 0.043 \\
\hline
\end{tabular}

$\mathrm{CI}$ : confidence interval. 
Additionally, a clinical cancer genetics program was established and operating smoothly with no major issues. Compliance on testing high-risk patients was recently added to our "Key Performance Indicators (KPI)," data on which are collected and reported by our quality office. We are also currently expanding our genetic testing and counseling program to include mutations in genes other than BRCA1 and BRCA2 for high-risk patients who were tested negative.

The current study has avoided many of the limitations we had in the previous study. The sample size is not an issue here, though larger studies are needed to study the contribution of each risk factor in its own or in combination to a positive mutation rate.

\section{Conclusions}

Our recent findings support the conclusion that $B R C A 1$ and $B R C A 2$ mutations are prevalent enough to be incorporated into clinical practice guidelines nationwide and to provide affected women with free access to risk reduction and reconstructive surgeries.

\section{Abbreviations}

\author{
CI: Confidence intervals \\ ER: $\quad$ Estrogen receptors \\ PR: Progesterone receptors \\ FISH: Fluorescent in situ hybridization \\ HER2: Human epidermal growth factor receptor \\ IHC: Immunohistochemistry \\ IRB: Institutional review board \\ MDT: Multidisciplinary team \\ NCCN: National comprehensive cancer network \\ VUS: Variant of uncertain significance.
}

\section{Data Availability}

Data will not be available online as it might contain sensitive information regarding the mutation status.

\section{Ethical Approval}

The study was approved by our Institutional Review Board (IRB).

\section{Consent}

All patients signed informed consent. Data submitted are entirely unidentifiable, and there are no details of individuals reported within the manuscript.

\section{Conflicts of Interest}

The authors declare that they have no conflicts of interest.

\section{Authors' Contributions}

The first author HA conceived the research idea, planned it, supervised data collection, and took the lead in writing the manuscript. The second author LA consulted with patients and supervised informed consent, sample collection, and genetic counselling. The third author DJ participated in analyzing the data and editing the manuscript. All authors have read and approved the manuscript.

\section{Acknowledgments}

The authors would like to acknowledge Dr. Abdelghani Tbakhi, Dr. Amal Al-Omari, their IRB, Mrs. Alice Haddadin, and Mrs. Lubna Al-Useily for their great help in conducting this research.

\section{References}

[1] Jordan Cancer Registry, "Cancer incidence in Jordan," in Non-Communicable Diseases Directorate Ministry of Health, Jordan Cancer Registry, Amman, Jordan, 2015, http://www. moh.gov.jo/Pages/viewpage.aspx?pageID $=240$.

[2] N. S. El Saghir, M. K. Khalil, T. Eid et al., "Trends in epidemiology and management of breast cancer in developing Arab countries: a literature and registry analysis," International Journal of Surgery, vol. 5, no. 4, pp. 225-233, 2007.

[3] L. Chouchane, H. Boussen, and K. S. R. Sastry, "Breast cancer in Arab populations: molecular characteristics and disease management implications," The Lancet Oncology, vol. 14, no. 10, pp. e417-e424, 2013.

[4] W. D. Foulkes, "Inherited susceptibility to common cancers," New England Journal of Medicine, vol. 359, no. 20, pp. 2143-2153, 2008.

[5] M. J. Larsen, M. Thomassen, A.-M. Gerdes, and T. A. Kruse, "hereditary breast cancer: clinical, pathological and molecular characteristics," Breast Cancer:Basic and Clinical Research, vol. 8, pp. 145-155, 2014.

[6] N. Mavaddat, S. Peock, D. Frost et al., "Cancer risks for BRCA1 and BRCA2 mutation carriers: results from prospective analysis of EMBRACE," JNCI: Journal of the National Cancer Institute, vol. 105, no. 11, pp. 812-822, 2013.

[7] S. Chen and G. Parmigiani, "Meta-analysis of BRCA1 and BRCA2 Penetrance," Journal of Clinical Oncology, vol. 25, no. 11, pp. 1329-1333, 2007.

[8] J. K. Litton, H. S. Rugo, J. Ettl et al., "Talazoparib in patients with advanced breast cancer and a germline BRCA mutation," New England Journal of Medicine, vol. 379, no. 8, pp. 753-763, 2018.

[9] M. E. Robson, N. Tung, P. Conte et al., "OlympiAD final overall survival and tolerability results: olaparib versus chemotherapy treatment of physician's choice in patients with a germline BRCA mutation and HER2-negative metastatic breast cancer," Annals of Oncology, vol. 30, no. 4, pp. 558-566, 2019.

[10] V. Diéras, H. Bonnefoi, E. Alba et al., "Iniparib administered weekly or twice-weekly in combination with gemcitabine/ carboplatin in patients with metastatic triple-negative breast cancer: a phase II randomized open-label study with pharmacokinetics," Breast Cancer Research and Treatment, vol. 177, no. 2, pp. 383-393, 2019.

[11] N. C. Turner, M. L. Telli, H. S. Rugo et al., "A phase II study of talazoparib after platinum or cytotoxic nonplatinum regimens in patients with advanced breast cancer and germline BRCA1/ 2 mutations (ABRAZO)," Clinical Cancer Research, vol. 25, no. 9, pp. 2717-2724, 2019.

[12] F. Karami and P. Mehdipour, "A comprehensive focus on global spectrum of BRCA1 and BRCA2 mutations in breast 
cancer," BioMed Research International, vol. 2013, pp. 1-21, 2013.

[13] N. Jalkh, J. Nassar-Slaba, E. Chouery et al., "Prevalance of BRCA1 and BRCA2 mutations in familial breast cancer patients in Lebanon," Hereditary Cancer in Clinical Practice, vol. 10, p. 7, 2012.

[14] A. Laraqui, N. Uhrhammer, I. Lahlou-Amine et al., "Mutation screening of the BRCA1 gene in early onset and familial breast/ovarian cancer in Moroccan population," International Journal of Medical Sciences, vol. 10, no. 1, pp. 60-67, 2013.

[15] S. S. Ibrahim, E. E. Hafez, and M. M. Hashishe, "Presymptomatic breast cancer in Egypt: role of BRCA1 and BRCA2 tumor suppressor genes mutations detection," Journal of Experimental and Clinical Cancer Research, vol. 29, no. 1, pp. 82-91, 2010.

[16] K. D. Awadelkarim, G. Aceto, S. Veschi et al., "BRCA1 and BRCA2 status in a central Sudanese series of breast cancer patients: interactions with genetic, ethnic and reproductive factors," Breast Cancer Research and Treatment, vol. 102, no. 2, pp. 189-199, 2007.

[17] T. N. Hasan, G. Shafi, N. A. Syed, M. A. Alsaif, A. A. Alsaif, and A. A. Alshatwi, "Lack of association of BRCA1 and BRCA2 variants with breast cancer in an ethnic population of Saudi arabia, an emerging high-risk area," Asian Pacific Journal of Cancer Prevention, vol. 14, no. 10, pp. 5671-5674, 2013.

[18] W. Troudi, N. Uhrhammer, K. B. Romdhane et al., "Complete mutation screening and haplotype characterization of BRCA1 gene in Tunisian patients with familial breast cancer," Cancer Biomarkers, vol. 4, no. 1, pp. 11-18, 2008.

[19] H. Abdel-Razeq, A. Al-Omari, F. Zahran, and B. Arun, "Germline BRCA1/BRCA2 mutations among high risk breast cancer patients in Jordan," BMC Cancer, vol. 18, no. 1, p. 152, 2018.

[20] Genetic/Familial high-risk assessment: breast and ovarian. https://www.nccn.org/professionals/physician_gls/pdf/ genetics_screening.pdf.

[21] C. Farra, C. Dagher, R. Badra et al., "BRCA mutation screening and patterns among high-risk Lebanese subjects," Hereditary Cancer Clinical Practice, vol. 17, no. 1, 2019.

[22] N. S. El Saghir, N. K. Zgheib, H. A. Assi et al., "BRCA1 and BRCA2 mutations in ethnic Lebanese Arab women with high hereditary risk breast cancer," The Oncologist, vol. 20, no. 4, pp. 357-364, 2015.

[23] K. Abdulrashid, N. AlHussaini, W. Ahmed, and L. Thalib, "Prevalence of BRCA mutations among hereditary breast and/ or ovarian cancer patients in Arab countries: systematic review and meta-analysis," BMC Cancer, vol. 19, no. 1, p. 256, 2019. 